\title{
Are Basophils Important Mediators for Helminth-Induced Th2 Immune Responses? A Debate
}

\author{
Sonia Leon-Cabrera and Ana Flisser \\ Departamento de Microbiología y Parasitología, Facultad de Medicina, Universidad Nacional Autónoma de México, \\ 04510 México, DF, Mexico \\ Correspondence should be addressed to Ana Flisser, flisser@unam.mx
}

Received 27 May 2011; Accepted 8 December 2011

Academic Editor: Abhay R. Satoskar

Copyright () 2012 S. Leon-Cabrera and A. Flisser. This is an open access article distributed under the Creative Commons Attribution License, which permits unrestricted use, distribution, and reproduction in any medium, provided the original work is properly cited.

Helminth parasites induce Th2 immune responses. Immunological mechanisms leading to Th2 induction are mainly dependent on IL-4. However, early source of IL-4 has not been precisely identified. Noticeably, basophils seem to be important mediators for inducing and maintaining the Th2 response probably because they secrete IL-4 and exert functions similar to APCs. Nevertheless, recent experimental evidence points that DCs could be also significant participants during this process. The involvement of basophils during memory responses is also discussed.

\section{Introduction}

Intestinal helminth infections still represent a public health problem in many developing tropical and subtropical countries affecting the health of human beings and of livestock $[1,2] . \mathrm{CD}^{+} \mathrm{T}$ cells are the main cellular mediators in host helminth interactions. In response to different antigens, these cells differentiate in four types of T-helper cells Th1, Th2, Th17, and regulatory T cells. Helminths and their antigens induce Th2 immune responses, and protection against these parasites seems to be dependent on this polarization.

Th2-cells secrete type 2 cytokines such as interleukin- 4 (IL-4), IL-5, IL-9, IL-13, but non-T cells including basophils, mast cells, B cells, and eosinophils can also produce them. The initial priming for Th2 differentiation is dependent on the IL-4 receptor $\alpha$ chain (IL-4R) and transcription factors STAT6 and GATA3, as well as processing and presenting antigens from antigen presenting cells (APCs) and upregulation of costimulatory molecules [3]. A type 2 immune response is characterized by activation and expansion of $\mathrm{CD} 4^{+} \mathrm{Th} 2-$ cells, mucosal epithelial cells, eosinophils, basophils, production of immunoglobulin E (IgE) and mast cell, and goblet cell hyperplasia [4]. Moreover, basophils and mast cells are activated by IgE-immune complexes through crosslinkedhigh-affinity Fc receptors (FcRs) for IgE located on the cell surface. Then, these cells are able to degranulate and release cytokines, chemokines, proteases, serotonin, histamine, and heparin, resulting in smooth muscle hypercontractibility, increased permeability, and inflammatory cell recruitment that, accompanied by mucus production, will facilitate clearance of parasites (Figure 1).

Basic aspects about activation of Th1- and Th17-type immune responses are well characterized. Nevertheless, the immunological mechanisms leading towards induction of Th2 immune responses remain to be elucidated. Early production of IL-4 is essential for Th2 differentiation [3]. Dendritic cells (DCs) are efficient APCs that express costimulatory molecules CD40 and CD86 and produce cytokines (IL-12, IL-13, and IL-6) necessary for the activation and differentiation of $\mathrm{CD} 4^{+} \mathrm{T}$ cells during Th1 or Th17 responses [5]. However, DCs are not able to produce IL-4.

Recently, it has been documented that basophils are involved in development and amplification of type 2 immune responses during helminth infections, because they are capable of producing and secreting IL-4 in response to helminth antigens and by crosslinking of antigen-specific IgE complexes. Furthermore, it has been suggested the possible role of basophils as APCs, since they constitutively express MHCclass-II, costimulatory molecules such as CD40, CD80, and CD86, and the lymph-node-homing receptor CD62L [6-8]. 


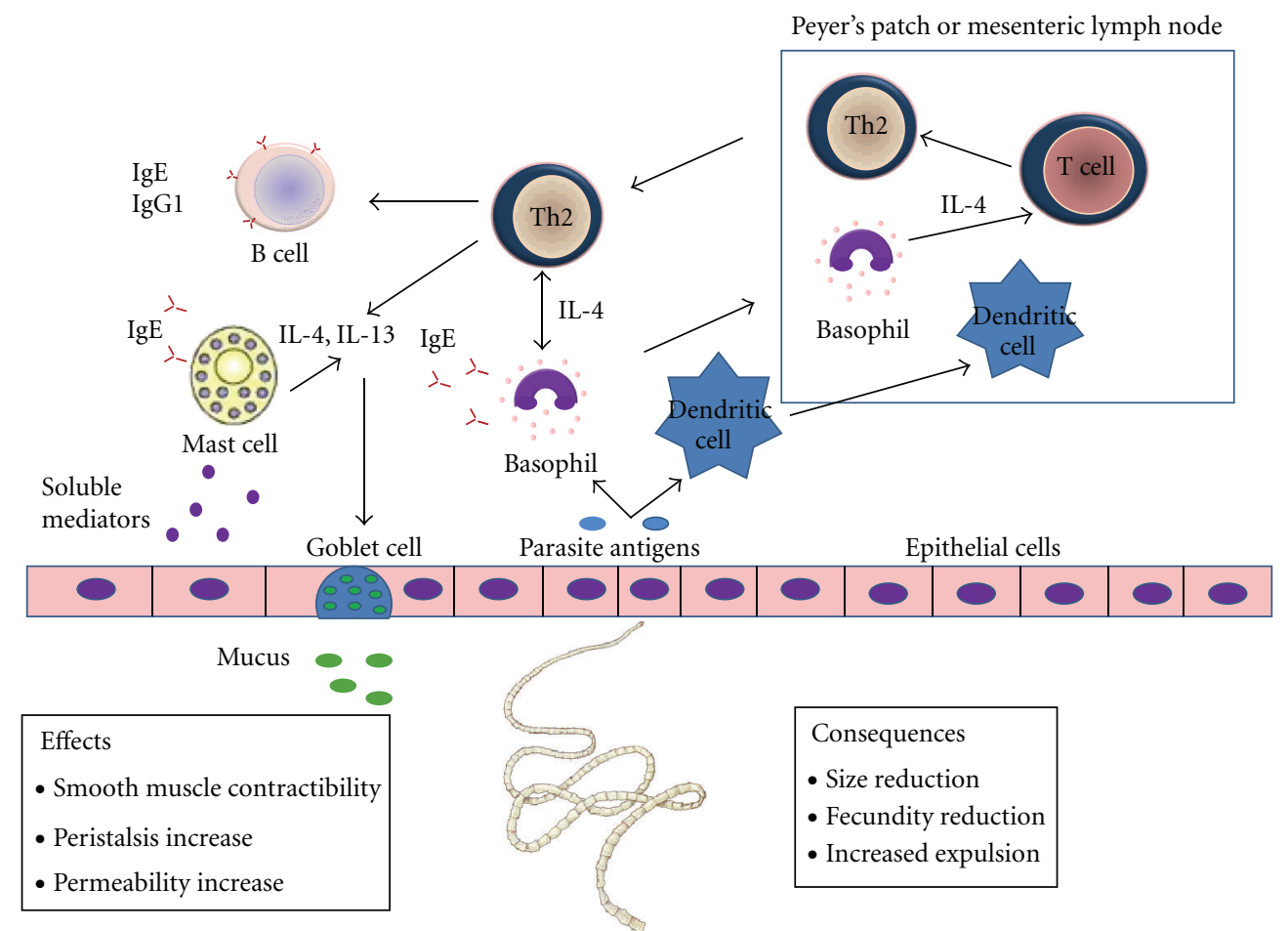

FIGURE 1: Components of type 2 immune response effective against gastrointestinal (GI) helminth parasites. In the primary response, APCs process and present antigens via MHC-class-II, upregulate costimulatory molecules, and, in an IL- 4 milieu, prime naïve T cells to become Th2-cells. Th2-cells and other reactive cells secrete IL-4 and IL-13, promoting B class switching to IgE and IgG1. IgE immune complexes activate basophils and mast cells by crosslinking of FcR. Activated mast cells and basophils secrete soluble mediators inducing changes in smooth muscle contractility, peristalsis, and intestinal permeability increase. IL-4 also induces goblet cell proliferation and mucus production. All of these elements induce a hostile environment for the parasite, provoking their expulsion or their reduction in size and fecundity.

This information indicates that this cell type is a potential early source of IL- 4 that could promote differentiation of $\mathrm{CD}^{+}{ }^{+} \mathrm{Th} 2$-cells or even present antigens to $\mathrm{CD} 4^{+} \mathrm{T}$ cells. Additionally, recent data have revealed a function of basophils not only in the initiation and maintenance of type 2 responses, but also in protective immunity and memory responses. Nonetheless, the potential enrolment of basophils in the initiation of Th2 immunity is under study, and results obtained from different research groups have become controversial, which highlights the importance of investigating the interactions between helminths and this cell type. The main goal of this paper is to provide an overview of recent findings in this regard.

\section{Cell Types Involved in Initiating and Maintaining Type 2 Immune Responses}

DCs control differentiation of naïve $\mathrm{T}$ cells into Th1 and Th17 effectors cells through cytokine production like IL-12, IL-6, and IL-23. After stimulation with Toll-like receptors' ligands, DCs initiate signal cascades resulting in presentation of peptides by MHC-class-II to $\mathrm{T}$ cells with upregulation of costimulatory molecules CD40, CD80, and CD86 [9]. Th1 response is promoted by IL-12 secretion from DCs [10] whereas Th17 by IL-1, IL-6, or IL-23 from this same APC [11].
The role of DCs in the induction of Th2 responses has also been studied [12], and it is well known that some Th2-type helminth antigens are able to modify DCs towards a phenotype that may induce Th2 differentiation [13-15]. However, Th2-associated DCs signals have not been identified yet. In spite of the fact that DC express MHC-classII and costimulatory molecules, very little is known about how DCs could sense Th2-type antigens, the nature of DCs subsets, whether they are sufficient to initiate Th2 responses, and if it is necessary establishing cooperation with innate immune cells.

Basophils are odd polymorphonuclear granulocytes, mainly found in the blood and peripheral tissues representing less than $1 \%$ of total leukocytes in blood and spleen. These cells mature in the bone-marrow before entering the blood stream, express FcRs and are capable of secreting Th2 cytokines such as IL-4 and thymic stromal lymphoprotein (TSLP), both important molecules for Th2 induction [16, 17]. Basophils can be activated through an IgE-dependent or IgE-independent process secreting, in consequence, important amounts of IL-4 $[18,19]$ as well as mediating degranulation and releasing preformed mediators [16].

Basophils are rapidly recruited into the bone-marrow, small intestine, blood stream, and other tissues during helminth infections and allergic inflammation $[20,21]$. 
Echinococcus multilocularis extracts as well as the glycoprotein IPSE/ $\alpha$-1 expressed in Schistosoma mansoni eggs induce release of IL-4 and IL-13 from basophils in the presence of IgE [22]. This demonstrates that basophils are able to respond to parasitic antigens and could be important in generating Th2 responses during helminth infections. Constitutively and under stimulation of allergens and helminth antigens, basophils express MHC-class-II and costimulatory molecules. Moreover, these cells rapidly produce IL-4 upon activation, and they are capable of forming conjugates with $\mathrm{CD}^{+} \mathrm{T}$ cells, suggesting a role for basophils in Th2 differentiation of naïve $\mathrm{CD} 4^{+} \mathrm{T}$ cells.

In the last decade, the role of basophils and DCs has been studied in experimental models where both cell populations were depleted mainly by different methods: treatment with the monoclonal antibody anti-FceRI (MAR-1) and administration of diphtheria toxin (DT) to animals that express the diphtheria toxin receptor under the CD11c promoter (CD11c-DTR), respectively. In 2010, a new genetically basophil-deficient mouse strain was developed [23]. Results induced discussion about the role of DCs and basophils in the initiation of Th2 responses. Studies from different groups regarding this topic are discussed what in follows.

\section{Basophils as Initiators of Type 2 Immune Responses}

Several reports have suggested that, in some conditions, DCs may not be crucial for promotion of the Th2-cell development. In the OVA-papain subcutaneous immunization model, a cysteine protease that mimics the activity of enzymes secreted by Th2 response-related helminth parasites promoted upregulation of MHC-class-II and costimulatory molecules expression in basophils, suggesting that these cells could exert functions similar to APCs [6]. Interestingly, transfer of OVA-loaded basophils into MHC-classII-deficient mice was sufficient for Th2 polarization, while MAR-1-mediated basophil depletion abolished this response, suggesting that antigen presentation by basophils was enough for triggering Th2 responses [6].

Splenic basophils from mice infected with Strongyloides venezuelensis were MHC-class-II positive. Furthermore, this cell population expressed CD80 and CD86, as well as CD62L, additionally showing secretion of IL-4 [7], in agreement with Sokol and colleagues [6]. In absence of DCs, basophils were able to induce development of antigen-specific Th2-cells in vitro, suggesting that these cells produce sufficient IL-4 for induction of naïve $\mathrm{CD}^{+} \mathrm{T}$ cells into Th2-cells. When basophils were incubated in the presence of antigen and IgE complexes, an enhanced Th2 response was observed, supporting that these cells could capture IgE complexes and increase their own ability as APC [7].

Parasite expulsion and protective immunity in Trichuris muris infection is dependent on $\mathrm{CD} 4^{+}$Th2-cells [24]. During this infection in mice, basophils were identified as a cell population that expressed IL-4, MHC class II, and CD62L [8], suggesting their potential to enter into lymphoid tissues, act as APC, produce IL-4, and lead T-cell polarization towards Th2-cells. In vivo depletion of basophils with MAR1 impaired immunity to this parasite, supporting that basophils could facilitate development of protective Th2 immunity. In T. muris-infected mice, exhibiting expression of MHC-class-II restricted to CD $11 \mathrm{c}^{+}$DC populations, animals showed minimal induction of Th2 cytokines in response to the infection. Interestingly, production of Th2 cytokines was restored when a neutralizing monoclonal antibody to IFN$\gamma$ was used [8]. These results suggest that DCs can induce protective Th2 responses in an environment where Th1 cytokines have been previously blocked, whereas basophils and other cell populations with ability to produce IL-4 could facilitate Th2 differentiation by reciprocal blocking Th1 responses.

Taken together, all these experiments using mice where basophils have been abrogated with specific antibodies (Table 1), support the idea that these cells could interact with $\mathrm{T}$ cells in order to promote Th2 differentiation through antigen presentation and cytokine production. Therefore, the role of DCs in the initiation of Th2 responses is questioned.

However, a recent study suggests that Th2-cell development cannot be so simple, requiring cooperation between DCs and basophils. Using the CD11c-DTR model, it has been demonstrated that DCs are required for the induction of antigen-specific Th2 responses after subcutaneous immunization with OVA-papain [25], in contrast to previous results by Sokol and coworkers [6]. Nevertheless, DCs isolated from these immunized mice failed to induce IL-4 production of OVA-specific $\mathrm{T}$ cells in vitro. When a combination of DCs and basophils was cocultured in presence of $\mathrm{T}$ cells, IL-4 production was clearly increased. Also, lymphnode DCs and dermal DCs released reactive oxygen species (ROS) after immunization with OVA-papain. Release of ROS induced the production of oxidized lipids that triggered induction of TSLP in epithelial cells [25]. TSLP has a key role in the induction of Th2 responses [26, 27]. In this way, the authors demonstrated that TSLP inhibit the ability of DCs to stimulate Th1 responses by suppressing IL-12 production in DCs and inducing production of CCL7. Remarkably, this chemokine could mediate the recruitment of IL-4 secreting basophils into the lymph-node promoting Th2 differentiation.

Other results support the notion of cooperation between DCs and basophils. For example, depletion of DCs in the CD11c-DTR model resulted in impaired production of Th2 cytokines from $\mathrm{CD}^{+} \mathrm{T}$ cells in response to Schistosoma mansoni infection or after S. mansoni egg injection [28]. On the contrary, depletion of basophils with MAR-1 did not alter levels of cytokines or Th2 induction in this experimental system. However, induction of the Th2 response was not completely ablated in CD11c-depleted animals suggesting that some DCs could remain or the involvement of other APCs. An additional study suggests that basophils are recruited into draining lymphatic nodes (dLNs) after S. mansoni egg injection [8]. In mice in which MHC-classII expression was restricted to $\mathrm{CD} 11 \mathrm{c}^{+} \mathrm{DC}$, $S$. mansoni egg injection increases $\mathrm{CD} 4^{+} \mathrm{T}$ cells in dLNs. Adoptive transfer of primary wild-type basophils augmented the proliferation 
TABLE 1: Experimental evidence related to the role of basophils and DC in induction of Th2 immunity.

\begin{tabular}{|c|c|c|}
\hline Reference & Methods employed & Conclusions \\
\hline$[6]$ & $\begin{array}{l}\text { OVA-papain immunization model } \\
\text { Basophil depletion mediated by MAR-1 } \\
\text { DC manipulation in CD11c-DTR model }\end{array}$ & $\begin{array}{l}\text { Basophils express MHC-class-II and costimulatory } \\
\text { molecules } \\
\text { DCs are not required for the development of } \\
\text { papain-induced Th2 responses } \\
\text { DCs are not able to induce CD4 } 4^{+} \text {Th2-cells in vitro } \\
\text { except if basophils are included in the culture }\end{array}$ \\
\hline$[8]$ & $\begin{array}{l}\text { T. muris-infected mice and injection of } S \text {. mansoni } \\
\text { eggs } \\
\text { Basophil depletion mediated by MAR-1 } \\
\text { DC manipulation in CD11c-DTR model }\end{array}$ & $\begin{array}{l}\text { Basophils express MHC-class-II and IL-4 } \\
\text { Depletion of basophils in vivo impairs immunity to } \\
\text { T. muris } \\
\text { Minimal induction of Th2 cytokines in mice in which } \\
\text { MHC-class-II expression was restricted to CD11c } \mathrm{c}^{+} \\
\text {cells. Th2 cytokines production was restored with a } \\
\text { neutralizing monoclonal antibody to interferon- } \gamma\end{array}$ \\
\hline [7] & S. venezuelensis-infected mice & $\begin{array}{l}\text { Basophils secrete IL-4 and express CD80, CD86, } \\
\text { CD62L, and MHC class II } \\
\text { Basophils induce antigen-specific Th2-cells in vitro in } \\
\text { the absence of DC } \\
\text { Enhanced Th2 responses result when basophils are } \\
\text { cultured with antigen-specific IgE }\end{array}$ \\
\hline$[48]$ & $\begin{array}{l}\text { N. brasiliensis infection } \\
\text { Basophil depletion mediated by anti-Thy- } 1.2 \mathrm{mAb}\end{array}$ & $\begin{array}{l}\text { In the absence of IL-4 and/or IL-13-producing T cells, } \\
\text { basophils contribute to efficient worm expulsion }\end{array}$ \\
\hline$[28]$ & $\begin{array}{l}\text { S. mansoni infection and S. mansoni egg injection } \\
\text { Basophil depletion mediated by MAR-1 } \\
\text { DC manipulation in CD11c-DTR model }\end{array}$ & $\begin{array}{l}\text { Depletion of DCs results in impaired CD } 4^{+} \mathrm{T} \text { cell } \\
\text { production of Th2 cytokines; depletion of basophils has } \\
\text { no effect }\end{array}$ \\
\hline [29] & $\begin{array}{l}\text { N. brasiliensis infection } \\
\text { Basophil depletion mediated by MAR-1 }\end{array}$ & $\begin{array}{l}\text { Depletion of basophils does not diminish the } \\
\text { development of IL- } 4 \text { producing CD } 4^{+} \mathrm{T} \text { cells } \\
\text { Basophils recruitment into the dLN depends on IL-3 }\end{array}$ \\
\hline$[23]$ & $\begin{array}{l}\text { OVA-papain immunization model and N. brasiliensis } \\
\text { infection } \\
\text { Basophil-deficient mice Mcpt8Cre and DC-ablated } \\
\text { mice }\end{array}$ & $\begin{array}{l}\text { Basophils are not required for in vivo priming of } \\
\text { Th2-cells in N. brasiliensis-infected mice or after } \\
\text { immunization with OVA-papain, with constitutive } \\
\text { deletion of basophils } \\
\text { DC-ablated mice are impaired in mounting a Th2-cell } \\
\text { response against OVA-papain despite normal basophil } \\
\text { recruitment }\end{array}$ \\
\hline
\end{tabular}

of $\mathrm{dLN} \mathrm{CD}^{+} \mathrm{T}$ cells in response to injection of parasite eggs [8], supporting that after exposure to helminth antigens basophils are recruited into dLN and they could cooperate together with DCs in the proliferation and expansion of CD $4^{+} \mathrm{T}$ cells.

Nevertheless, recent studies have questioned the use of DT for depleting DCs, claiming side effects of DT administration. Furthermore, the use of MAR-1 for depleting basophils has been related with activation of mast cells and induction of anaphylaxis. Then, in 2010, Ohnmacht and coworkers [23] reported a new transgenic mouse strain (Mcpt8Cre) with constitutive deletion of basophils. After immunization with OVA-papain, Mcpt8Cre mice developed a normal Th2-cell response suggesting that in papaininduced Th2-cell differentiation, basophils play a minor role. In addition, mice with constitutive deletion of DCs are impaired in mounting a Th2-cell response against OVApapain despite normal basophil recruitment, confirming that papain-induced Th2-cell differentiation depends on DC and not on basophils (Table 1). Similar results were obtained with
$N$. brasiliensis-infected mice where basophils seem not be required for in vivo priming of Th2-cells [23, 29]. Interestingly, excretion/secretion (E/S) products from $N$. brasiliensis and Acanthocheilonema viteae, as well as S. mansoni soluble egg antigen and Echinococcus granulosus antigen B [30], have been related with inhibition of DCs maturation and DC production of IL-10, favoring a Th2 response [31]. Recently, it has been demonstrated that excreted-secreted antigens of the cestode Taenia crassiceps (TcES) affect murine and human DC activities [32, 33]. DCs pulsed with TcES abrogated their capacity to respond to proinflammatory stimuli such as LPS, decreasing expression of maturation and costimulatory molecules. TcES-exposed murine bone-marrow-derived DCs failed to release proinflammatory cytokines, while they preserved IL-10 production [32]. Similarly, TcES enhances production of IL-10 by human DCs, but not IL-12, IL$1 \beta$, TNF, and IL-6 [33]. Additionally, when TcES-exposed DCs are used as APCs, they suppress IFN- $\gamma$ production and increase IL-4 levels in CD $4^{+} \mathrm{T}$ cells, supporting the idea that helminth-derived products may modulate DCs in order 
to acquire a special phenotype with capacity to bias Th2 responses. In spite that $T$. crassiceps shares antigenic resemblance with Taenia solium, the cestode parasite of humans [34], studies are necessary to analyze the role of basophils and DCs in the induction of Th2 responses because there are no published reports, except those performed in experimental infections with $T$. solium in hamsters. The intestinal mucosa shows an increase in IFN- $\gamma$ expression detected by in situ hybridization during the first week of infection while IL13 is seen between days 2 and 16 after infection and IL4 since the second week when parasite expulsion occurs. These findings demonstrate that coexpression of Th1 and Th2 cytokines takes place in this experimental infection [35]. It would be interesting to determine whether T. soliumexcreted/-secreted antigens have the ability to interact with DCs and basophils, in order to elucidate important early steps in the activation of the host immune response resulting in the expression of Th1 or Th2 cytokines.

Some authors propose that DCs alone can drive Th2-cell differentiation and basophils could help to sustain and amplify the type 2 response [36]. However, the multiple studies described, demonstrate the importance of basophils and DCs in the induction of Th2 responses, suggesting that there are several pathways in which these cells can act independently or in cooperation. The vision of the type $2 \mathrm{im}-$ mune response are like a complex network with duplicated essential functions which indicates that basophil-dependent response, DC-dependent response, and DC/basophil-dependent response could simultaneously occur in vivo. Therefore, it is necessary to reassess the role of each one depending on the infection setting.

\section{Participation of Basophils in Memory Response against Helminths}

The high prevalence of helminths in endemic populations suggests that the complete elimination of parasites is seldom generated [37]. However, some evidence about the rapid development of resistance to reinfection in individuals with long-term exposure [38] and the decrease of infection intensity in adults of endemic areas [39] indicates that immunity is acquired with cumulative exposure. The long exposure or persistence of antigens keeps the immunological memory due to long-term survival by antigen-specific memory $\mathrm{T}$ cells and B cells [40]. Then, antibody production by memory B cells is a key process for maintaining the acquired immune response. Noticeably, helminth infections are characterized by IgE production, and high levels of this antibody class are associated with resistance to reinfection $[41,42]$.

Basophils are capable of binding antigen-specific IgE antibodies through FcR and undergo activation [16]. This fact is important during secondary infections with parasites. Interestingly, experimental evidence shows that mechanisms required for parasite expulsion during primary and secondary infections are different. During primary mice infection with $N$. brasiliensis, a protective immune response dependent on IL-13, IL-4, and CD4 ${ }^{+} \mathrm{T}$ cells develops, which is able to stimulate goblet cell proliferation, mucin secretion, and physiological changes in the gut; eosinophils, IgE, and accumulation of basophils are not necessary for expulsion in a primary infection $[23,43,44]$. During secondary infections, worm expulsion occurs in mast-cell-deficient c$\mathrm{Kit}^{\mathrm{W} \text {-sh }}$ mice, even in the absence of $\mathrm{CD} 4^{+} \mathrm{T}$ cells. However, when these mice were depleted of basophils, worm expulsion was impaired [45]. These data indicate that, in a primary infection, $\mathrm{CD}^{+} \mathrm{T}$ cells stimulate a non-CD4 ${ }^{+} \mathrm{T}$-cell group involved in the memory response which could participate in the expulsion of worms after a secondary infection. In agreement with these results, Mcpt8-basophils-deficient mice showed an efficient $N$. brasiliensis worm expulsion during the primary infection, while this ability was impaired during the secondary infection [23]. These studies suggest that basophils play a role in the protective immunity against helminths.

Yoshimoto and colleagues [7] reported that basophils might efficiently take up low doses of antigen in an IgE-dependent way. Moreover, when these cells are pulsed with antigen-IgE complexes, they are capable of improving their APCs ability. In secondary infections, basophils could bind IgE and become sensitized to antigens that have been previously in contact with the host. Sensitized basophils can synthesize and release IL-4 and IL-13 [46], both key molecules for B-cell differentiation and IgE production [47]. This information highlights the possibility of an amplification loop between basophil activation and immunoglobulin production. Also, basophils could be directly activated by some allergens and parasites $[6,46]$ expanding their own capacity for introducing excretory or secretory proteins from helminths and promoting Th2 differentiation.

Basophils have been shown to be able to enhance immunological memory responses. In mice immunized with allophycocyanin, basophils exert the ability to in vitro bind this protein on their cell surface, becoming activated and releasing IL- 4 and IL- 6 after 6 weeks of immunization. This activation is FCR dependent, as no release of IL-4 and IL-6 was detectable on FcR-deficient mice [49]. Therefore, it has been proposed that after a primary immunization, antigenspecific IgE is captured by FCR on basophils and, after a second one, activation occurs releasing major cytokines for B-cell stimulation and in consequence immunoglobulin production [49]. Recent studies have shown that IgD-crosslinking leads to basophil activation and expression of B-cellactivating factor (BAFF) and IL-4, stimulating production of T-independent antibodies from B cells [50]. Also, KU812 cells, a human basophilic line, are capable of producing IL-4 and IL-13, and induce synthesis of IgE and IgG4 in human normal B cells [51]. During memory response, secretion of these cytokines could be important since depletion of basophils leads to decrease of production of IgG1 and IgG2 as well as increase of susceptibility to Streptococcus pneumoniainduced sepsis [49]. These results indicate that basophils may not only contribute to support the Th2 response through IL4 production but also by directly activating and promoting IgE production from B cells.

In a primary infection, the immune response takes longer to develop, probably because of the higher number of parasite antigens that need to be recognized in order to induce the host immune response [52]. In addition, in 


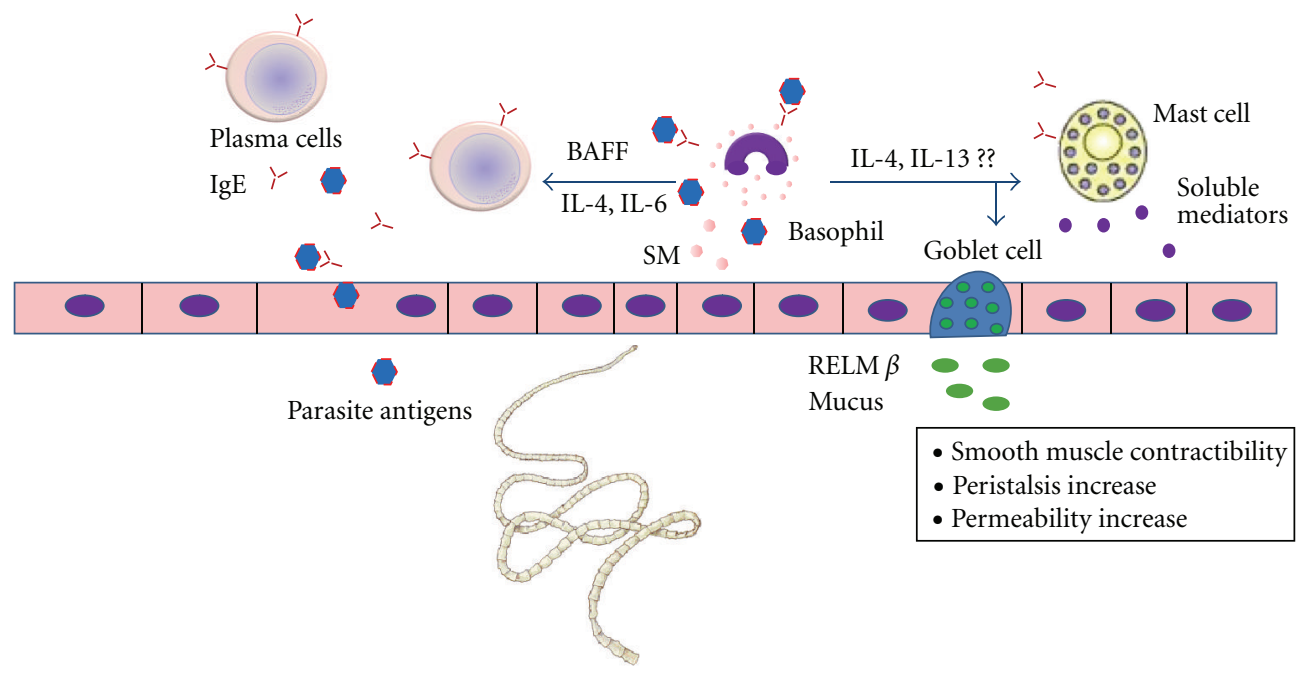

FIGURE 2: Possible role of basophils in secondary immune responses against GI helminths. Basophils could be directly activated by parasite antigens or take up antigen through parasite-specific IgE antibodies developed in previous infections. IL-4, IL-13, IL-6, and BAFF, released by activated basophils, stimulate antibody production from B cells and may enhance Th2-associated immune responses. It remains to be determined if these mechanisms take place in vivo. SM: soluble mediators.

Heligmosomoides polygyrus-infected mice most of the IgG1 and IgE antibodies are polyclonal or have low-affinity specificities; comparatively, after multiple infections affinity of specific IgG and IgA antibodies matured preventing adult worm development [53]. It has been suggested that parasites possess the ability to promote nonspecific-antibody production, but this topic is currently under study. In spite of the fact that development and maintenance of long-lived IgE-producing plasma cells remains unclear, both induction of specific IgE-producing plasma cells during a primary infection and development of high-affinity antibodies during repetitive infections could explain the rapid basophil activation during secondary infections. Remarkably, it has been shown that, after immunization, basophils, additional to B cells, are the only population able to capture on their surface intact antigens present in the plasma through a mechanism mediated by antigen-specific IgE antibodies [54].

All this information suggests that during secondary challenges specific- $\operatorname{IgE}$ antibodies and parasite-derived products could activate basophils. Production of IL-4, IL-6, and BAFF by activated basophils may stimulate T-independent antibody production from $\mathrm{B}$ cells resulting in an amplification loop. Local release of IL-4 and IL-13 could stimulate other innate cells like goblet and mast cells, leading to an effective and more rapid protective response (Figure 2).

Oral immunization with recombinant functional Taenia solium calreticulin ( $\mathrm{rTsCRT}$ ) reduces tapeworm burden in the experimental model of intestinal taeniasis in hamsters [55]. Calreticulin has been identified in several parasites $[56,57]$, and it has been demonstrated that CRT-specific IgE antibodies develop in many infections $[58,59]$. In addition, basophils isolated from individuals living in a hookworm endemic area are able to release histamine in the presence of CRT [60], suggesting the existence of basophils precharged with CRT-specific IgE antibodies. CRT is also recognized by IgE antibodies of Heligmosomoides polygyrus-infected mice and induces degranulation of an IgE-sensitized basophil cell line [58]. Therefore, it could be interesting to analyze if TsCRT immunization is able to induce antigen-specific IgE production and, if these antibodies are able to sensitize basophils. Sensitized basophils can synthesize and release IL4 and IL-13 promoting Th2 differentiation and helping to support a protective immune response. Elucidation of these mechanisms will allow the development or more efficient vaccines against helminths.

\section{Concluding Remarks}

Helminths induce Th2 immune responses. Immunological mechanisms leading to Th2 induction are mainly dependent on IL-4. However, early source of IL-4 has not been precisely identified. Noticeably, basophils seem to be important mediators for inducing and maintaining the Th2 response probably because they secrete IL- 4 and exert functions similar to APCs. Nevertheless, recent experimental evidence points that DCs could be also significant participants during this process, suggesting that Th2 immune responses could be occurring through multiple nonexcluding pathways, which have not been completely elucidated yet. Also, it is necessary to analyze these findings under an overall view since the nature of the immune response depends on the characteristics of individual products as well as the particular interactions of each helminth with its host. Finally, although the role of basophils in the induction of memory responses against helminths needs further investigation, it opens an interesting research field focused on developing vaccines based on antigens that promote Th2 responses, long-lived plasma cells, and specific antibody production. 


\section{Acknowledgment}

S. Leon-Cabrera had a Ph.D. fellowship from Consejo Nacional de Ciencia y Tecnología (CONACYT) at the Programa de Doctorado en Ciencias Biomédicas, UNAM.

\section{References}

[1] R. Bungiro and M. Cappello, "Hookworm infection: new developments and prospects for control," Current Opinion in Infectious Diseases, vol. 17, no. 5, pp. 421-426, 2004.

[2] P. J. Hotez, J. Bethony, M. E. Bottazzi, S. Brooker, D. Diemert, and A. Loukas, "New technologies for the control of human hookworm infection," Trends in Parasitology, vol. 22, no. 7, pp. 327-331, 2006.

[3] K. A. Mowen and L. H. Glimcher, "Signaling pathways in Th2 development," Immunological Reviews, vol. 202, pp. 203-222, 2004.

[4] R. M. Anthony, L. I. Rutitzky, J. F. Urban Jr., M. J. Stadecker, and W. C. Gause, "Protective immune mechanisms in helminth infection," Nature Reviews Immunology, vol. 7, no. 12, pp. 975-987, 2007.

[5] C. A. Janeway Jr. and R. Medzhitov, "Innate immune recognition," Annual Review of Immunology, vol. 20, pp. 197-216, 2002.

[6] C. L. Sokol, N. Q. Chu, S. Yu, S. A. Nish, T. M. Laufer, and R. Medzhitov, "Basophils function as antigen-presenting cells for an allergen-induced T helper type 2 response," Nature Immunology, vol. 10, no. 7, pp. 713-720, 2009.

[7] T. Yoshimoto, K. Yasuda, H. Tanaka et al., "Basophils contribute to $\mathrm{T}_{H} 2-\operatorname{IgE}$ responses in vivo via IL-4 production and presentation of peptide-MHC class II complexes to $\mathrm{CD}^{+} \mathrm{T}$ cells," Nature Immunology, vol. 10, no. 7, pp. 706-712, 2009.

[8] J. G. Perrigoue, S. A. Saenz, M. C. Siracusa et al., "MHC class II-dependent basophil-CD4 ${ }^{+} \mathrm{T}$ cell interactions promote $\mathrm{T}_{H} 2$ cytokine-dependent immunity," Nature Immunology, vol. 10, no. 7, pp. 697-705, 2009.

[9] J. Banchereau, F. Briere, C. Caux et al., "Immunobiology of dendritic cells," Annual Review of Immunology, vol. 18, pp. 767-811, 2000.

[10] G. Trinchieri, "Interleukin-12 and the regulation of innate resistance and adaptive immunity," Nature Reviews Immunology, vol. 3, no. 2, pp. 133-146, 2003.

[11] E. V. Acosta-Rodriguez, G. Napolitani, A. Lanzavecchia, and F. Sallusto, "Interleukins $1 \beta$ and 6 but not transforming growth factor- $\beta$ are essential for the differentiation of interleukin 17producing human T helper cells," Nature Immunology, vol. 8, no. 9, pp. 942-949, 2007.

[12] R. Maldonado-López, T. De Smedt, P. Michel et al., "CD8 $8 \alpha^{+}$ and $\mathrm{CD} 8 \alpha^{-}$Subclasses of dendritic cells direct the development of distinct T helper cells in vivo," Journal of Experimental Medicine, vol. 189, no. 3, pp. 587-592, 1999.

[13] G. Perona-Wright, S. J. Jenkins, and A. S. MacDonald, "Dendritic cell activation and function in response to Schistosoma mansoni," International Journal for Parasitology, vol. 36, no. 6, pp. 711-721, 2006.

[14] D. van der Kleij, E. Latz, J. F. H. M. Brouwers et al., "A novel host-parasite lipid cross-talk. Schistosomal lyso-phosphatidylserine activates toll-like receptor 2 and affects immune polarization," The Journal of Biological Chemistry, vol. 277, no. 50, pp. 48122-48129, 2002.

[15] B. Everts, G. Perona-Wright, H. H. Smits et al., "Omega-1, a glycoprotein secreted by Schistosoma mansoni eggs, drives Th2 responses," Journal of Experimental Medicine, vol. 206, no. 8, pp. 1673-1680, 2009.

[16] J. T. Schroeder, "Basophils beyond effector cells of allergic inflammation," Advances in Immunology, vol. 101, pp. 123-161, 2009.

[17] R. A. Seder, W. E. Paul, A. M. Dvorak et al., "Mouse splenic and bone marrow cell populations that express high-affinity $\mathrm{Fc}(\varepsilon)$ receptors and produce interleukin 4 are highly enriched in basophils," Proceedings of the National Academy of Sciences of the United States of America, vol. 88, no. 7, pp. 2835-2839, 1991.

[18] R. A. Seder, M. Plaut, S. Barbieri, J. F. Urban Jr., F. D. Finkelman, and W. E. Paul, "Purified Fc epsilon R+ bone marrow and splenic non- $\mathrm{B}$, non-T cells are highly enriched in the capacity to produce IL-4 in response to immobilized IgE, IgG2a, or ionomycin," The Journal of Immunology, vol. 147, no. 3, pp. 903-909, 1991.

[19] E. Mitre, R. T. Taylor, J. Kubofcik, and T. B. Nutman, "Parasite antigen-driven basophils are a major source of IL-4 in human filarial infections," The Journal of Immunology, vol. 172, no. 4, pp. 2439-2445, 2004.

[20] B. Min, M. Prout, J. Hu-Li et al., "Basophils produce IL-4 and accumulate in tissues after infection with a Th2-inducing parasite," Journal of Experimental Medicine, vol. 200, no. 4, pp. 507-517, 2004.

[21] B. F. Gibbs, "Human basophils as effectors and immunomodulators of allergic inflammation and innate immunity," Clinical and Experimental Medicine, vol. 5, no. 2, pp. 43-49, 2005.

[22] E. Aumüller, G. Schramm, A. Gronow et al., "Echinococcus multilocularis metacestode extract triggers human basophils to release interleukin-4," Parasite Immunology, vol. 26, no. 10, pp. 387-395, 2004.

[23] C. Ohnmacht, C. Schwartz, M. Panzer, I. Schiedewitz, R. Naumann, and D. Voehringer, "Basophils orchestrate chronic allergic dermatitis and protective immunity against helminths," Immunity, vol. 33, no. 3, pp. 364-374, 2010.

[24] L. J. Cliffe and R. K. Grencis, "The Trichuris muris system: a paradigm of resistance and susceptibility to intestinal nematode infection," Advances in Parasitology, vol. 57, pp. 255-307, 2004.

[25] H. Tang, W. Cao, S. P. Kasturi et al., "The T helper type 2 response to cysteine proteases requires dendritic cell-basophil cooperation via ROS-mediated signaling," Nature Immunology, vol. 11, no. 7, pp. 608-617, 2010.

[26] M. Rimoldi, M. Chieppa, V. Salucci et al., "Intestinal immune homeostasis is regulated by the crosstalk between epithelial cells and dendritic cells," Nature Immunology, vol. 6, no. 5, pp. 507-514, 2005.

[27] A. Al-Shami, R. Spolski, J. Kelly, A. Keane-Myers, and W. J. Leonard, "A role for TSLP in the development of inflammation in an asthma model," Journal of Experimental Medicine, vol. 202, no. 6, pp. 829-839, 2005.

[28] A. T. Phythian-Adams, P. C. Cook, R. J. Lundie et al., "CD11c depletion severely disrupts Th2 induction and development in vivo," Journal of Experimental Medicine, vol. 207, no. 10, pp. 2089-2096, 2010.

[29] S. Kim, M. Prout, H. Ramshaw, A. F. Lopez, G. LeGros, and B. Min, "Cutting edge: basophils are transiently recruited into the draining lymph nodes during helminth infection via IL3, but infection-induced Th2 immunity can develop without basophil lymph node recruitment or IL-3," The Journal of Immunology, vol. 184, no. 3, pp. 1143-1147, 2010. 
[30] R. Riganò, B. Buttari, E. Profumo et al., "Echinococcus granulosus antigen B impairs human dendritic cell differentiation and polarizes immature dendritic cell maturation towards a Th2 cell response," Infection and Immunity, vol. 75, no. 4, pp. 1667-1678, 2007.

[31] A. S. MacDonald and R. M. Maizels, "Alarming dendritic cells for Th2 induction," Journal of Experimental Medicine, vol. 205, no. 1, pp. 13-17, 2008.

[32] C. A. Terrazas, L. Gómez-García, and L. I. Terrazas, "Impaired pro-inflammatory cytokine production and increased Th2biasing ability of dendritic cells exposed to Taenia excreted/ secreted antigens: a critical role for carbohydrates but not for STAT6 signaling," International Journal for Parasitology, vol. 40, no. 9, pp. 1051-1062, 2010.

[33] C. A. Terrazas, F. Sánchez-Muñoz, A. M. Mejía-Domínguez et al., "Cestode antigens induce a tolerogenic-like phenotype and inhibit LPS in-flammatory responses in human dendritic cells," International Journal of Biological Sciences, vol. 7, no. 9, pp. 1391-1400, 2011.

[34] N. M. Espindola, A. H. Iha, I. Fernandes et al., "Cysticercosis immunodiagnosis using 18- and 14-kilodalton proteins from Taenia crassiceps cysticercus antigens obtained by immunoaffinity chromatography," Journal of Clinical Microbiology, vol. 43, no. 7, pp. 3178-3184, 2005.

[35] G. Avila, L. Aguilar, M. Romero-Valdovinos, F. Garcia-Vazquez, and A. Flisser, "Cytokine response in the intestinal mucosa of hamsters infected with Taenia solium," Annals of the New York Academy of Sciences, vol. 1149, pp. 170-173, 2008.

[36] J. E. Allen and R. M. Maizels, "Diversity and dialogue in immunity to helminths," Nature Reviews Immunology, vol. 11, no. 6, pp. 375-388, 2011.

[37] P. J. Hotez, P. J. Brindley, J. M. Bethony, C. H. King, E. J. Pearce, and J. Jacobson, "Helminth infections: the great neglected tropical diseases," The Journal of Clinical Investigation, vol. 118, no. 4, pp. 1311-1321, 2008.

[38] C. L. Black, P. N. M. Mwinzi, E. M. O. Muok et al., "Influence of exposure history on the immunology and development of resistance to human Schistosomiasis mansoni," PLoS Neglected Tropical Diseases, vol. 4, no. 3, article e637, 2010.

[39] A. E. Butterworth, A. J. Fulford, D. W. Dunne, J. H. Ouma, and R. F. Sturrock, "Longitudinal studies on human schistosomiasis," Philosophical Transactions of the Royal Society of London. Series B, vol. 321, no. 1207, pp. 495-511, 1988.

[40] L. J. McHeyzer-Williams and M. G. McHeyzer-Williams, "Antigen-specific memory B cell development," Annual Review of Immunology, vol. 23, pp. 487-513, 2005.

[41] D. W. Dunne, A. E. Butterworth, A. J. C. Fulford et al., "Immunity after treatment of human schistosomiasis: association between IgE antibodies to adult worm antigens and resistance to reinfection," European Journal of Immunology, vol. 22, no. 6, pp. 1483-1494, 1992.

[42] P. Rihet, C. E. Demeure, A. Bourgois, A. Prata, and A. J. Dessein, "Evidence for an association between human resistance to Schistosoma mansoni and high anti larval IgE levels," European Journal of Immunology, vol. 21, no. 11, pp. 2679-2686, 1991.

[43] D. Voehringer, T. A. Reese, X. Huang, K. Shinkai, and R. M. Locksley, "Type 2 immunity is controlled by IL-4/IL-13 expression in hematopoietic non-eosinophil cells of the innate immune system," Journal of Experimental Medicine, vol. 203, no. 6, pp. 1435-1446, 2006.

[44] F. D. Finkelman, T. Shea-Donohue, S. C. Morris et al., "Interleukin-4- and interleukin-13-mediated host protection against intestinal nematode parasites," Immunological Reviews, vol. 201, pp. 139-155, 2004.
[45] C. Ohnmacht and D. Voehringer, "Basophils protect against reinfection with hookworms independently of mast cells and memory Th2 cells," The Journal of Immunology, vol. 184, no. 1, pp. 344-350, 2010.

[46] C. Phillips, W. R. Coward, D. I. Pritchard, and C. R. A. Hewitt, "Basophils express a type 2 cytokine profile on exposure to proteases from helminths and house dust mites," Journal of Leukocyte Biology, vol. 73, no. 1, pp. 165-171, 2003.

[47] L. B. Bacharier and R. S. Geha, "Molecular mechanisms of IgE regulation," Journal of Allergy and Clinical Immunology, vol. 105, no. 2, part 2, pp. S547-S558, 2000.

[48] C. Ohnmacht and D. Voehringer, "Basophil effector function and homeostasis during helminth infection," Blood, vol. 113, no. 12, pp. 2816-2825, 2009.

[49] A. Denzel, U. A. Maus, M. R. Gomez et al., "Basophils enhance immunological memory responses," Nature Immunology, vol. 9, no. 7, pp. 733-742, 2008.

[50] K. Chen, W. Xu, M. Wilson et al., "Immunoglobulin D enhances immune surveillance by activating antimicrobial, proinflammatory and B cell-stimulating programs in basophils," Nature Immunology, vol. 10, no. 8, pp. 889-898, 2009.

[51] Y. Yanagihara, K. Kajiwara, Y. Basaki, K. Ikizawa, K. Akiyama, and H. Saito, "Induction of human IgE synthesis in B cells by a basophilic cell line, KU812," Clinical and Experimental Immunology, vol. 108, no. 2, pp. 295-301, 1997.

[52] M. Yazdanbakhsh and D. L. Sacks, "Why does immunity to parasites take so long to develop?" Nature Reviews Immunology, vol. 10, no. 2, pp. 80-81, 2010.

[53] K. D. McCoy, M. Stoel, R. Stettler et al., "Polyclonal and specific antibodies mediate protective immunity against enteric helminth infection," Cell Host and Microbe, vol. 4, no. 4, pp. 362-373, 2008.

[54] M. Mack, M. A. Schneider, C. Moll et al., "Identification of antigen-capturing cells as basophils," The Journal of Immunology, vol. 174, no. 2, pp. 735-741, 2005.

[55] S. León-Cabrera, M. Cruz-Rivera, F. Mendlovic et al., "Standardization of an experimental model of human taeniosis for oral vaccination," Methods, vol. 49, no. 4, pp. 346-350, 2009.

[56] N. El Gengehi, R. El Ridi, N. Abdel Tawab, M. El Demellawy, and B. L. Mangold, "A Schistosoma mansoni $62-\mathrm{kDa}$ band is identified as an irradiated vaccine T-cell antigen and characterized as calreticulin," Journal of Parasitology, vol. 86, no. 5, pp. 993-1000, 2000.

[57] G. Kasper, A. Brown, M. Eberl et al., "A calreticulin-like molecule from the human hookworm Necator americanus interacts with $\mathrm{Clq}$ and the cytoplasmic signalling domains of some integrins," Parasite Immunology, vol. 23, no. 3, pp. 141$152,2001$.

[58] J. Rzepecka, R. Lucius, M. Doligalska, S. Beck, S. Rausch, and S. Hartmann, "Screening for immunomodulatory proteins of the intestinal parasitic nematode Heligmosomoides polygyrus," Parasite Immunology, vol. 28, no. 9, pp. 463-472, 2006.

[59] J. Rzepecka, S. Rausch, C. Klotz et al., "Calreticulin from the intestinal nematode Heligmosomoides polygyrus is a Th2skewing protein and interacts with murine scavenger receptorA," Molecular Immunology, vol. 46, no. 6, pp. 1109-1119, 2009.

[60] D. I. Pritchard, D. S. W. Hooi, A. Brown, M. J. Bockarie, R. Caddick, and R. J. Quinnell, "Basophil competence during hookworm (Necator americanus) infection," American Journal of Tropical Medicine and Hygiene, vol. 77, no. 5, pp. 860-865, 2007. 

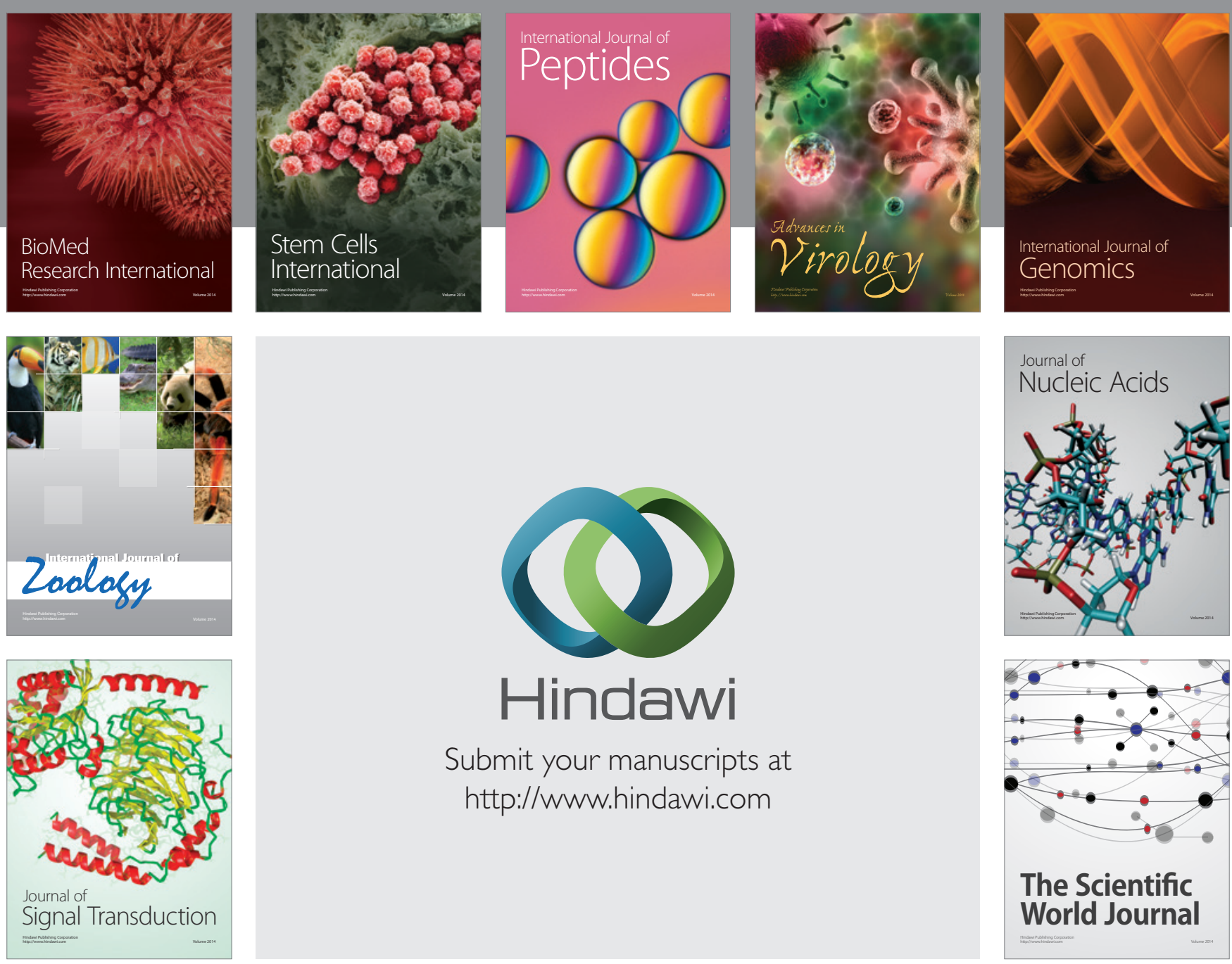

Submit your manuscripts at

http://www.hindawi.com
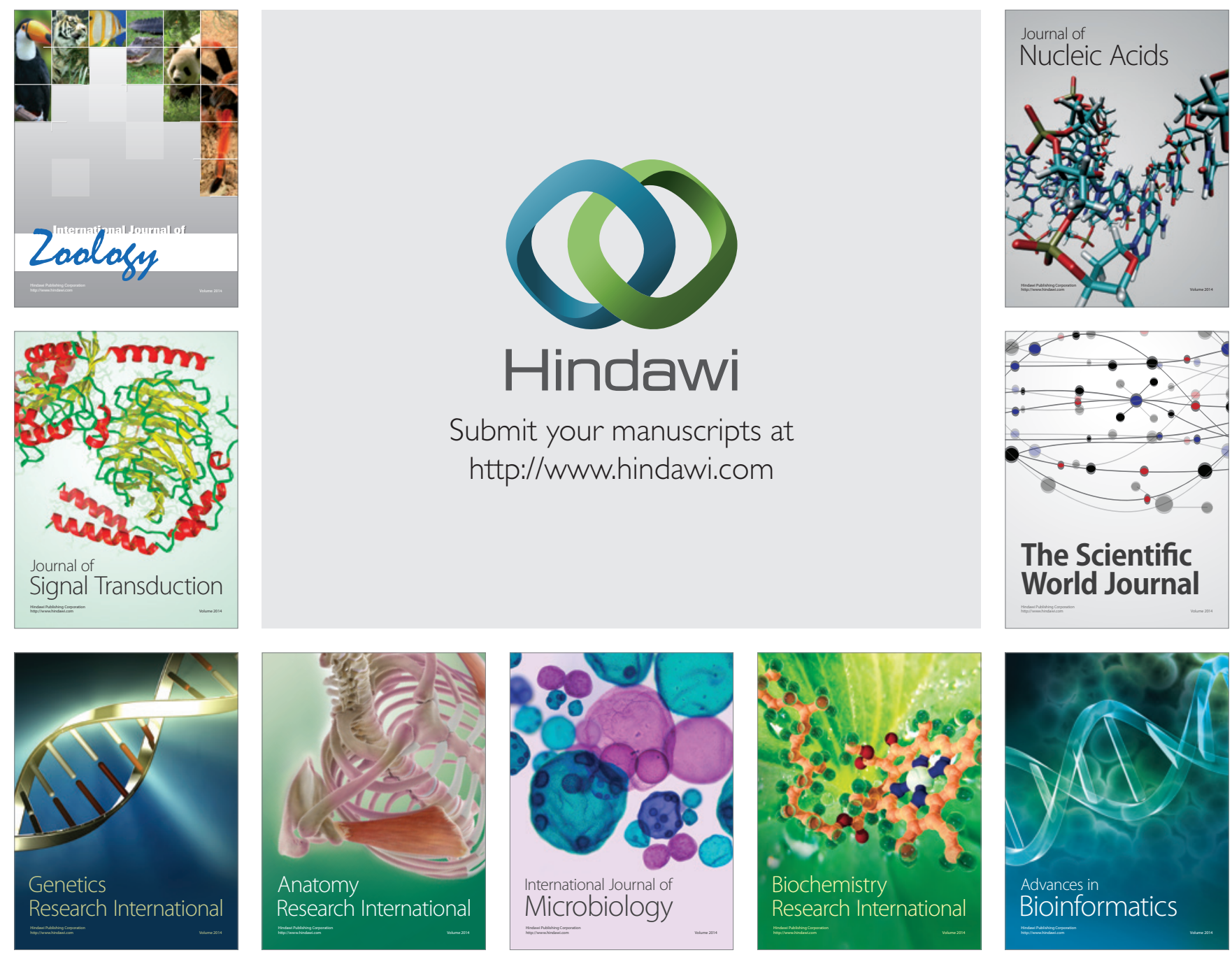

The Scientific World Journal
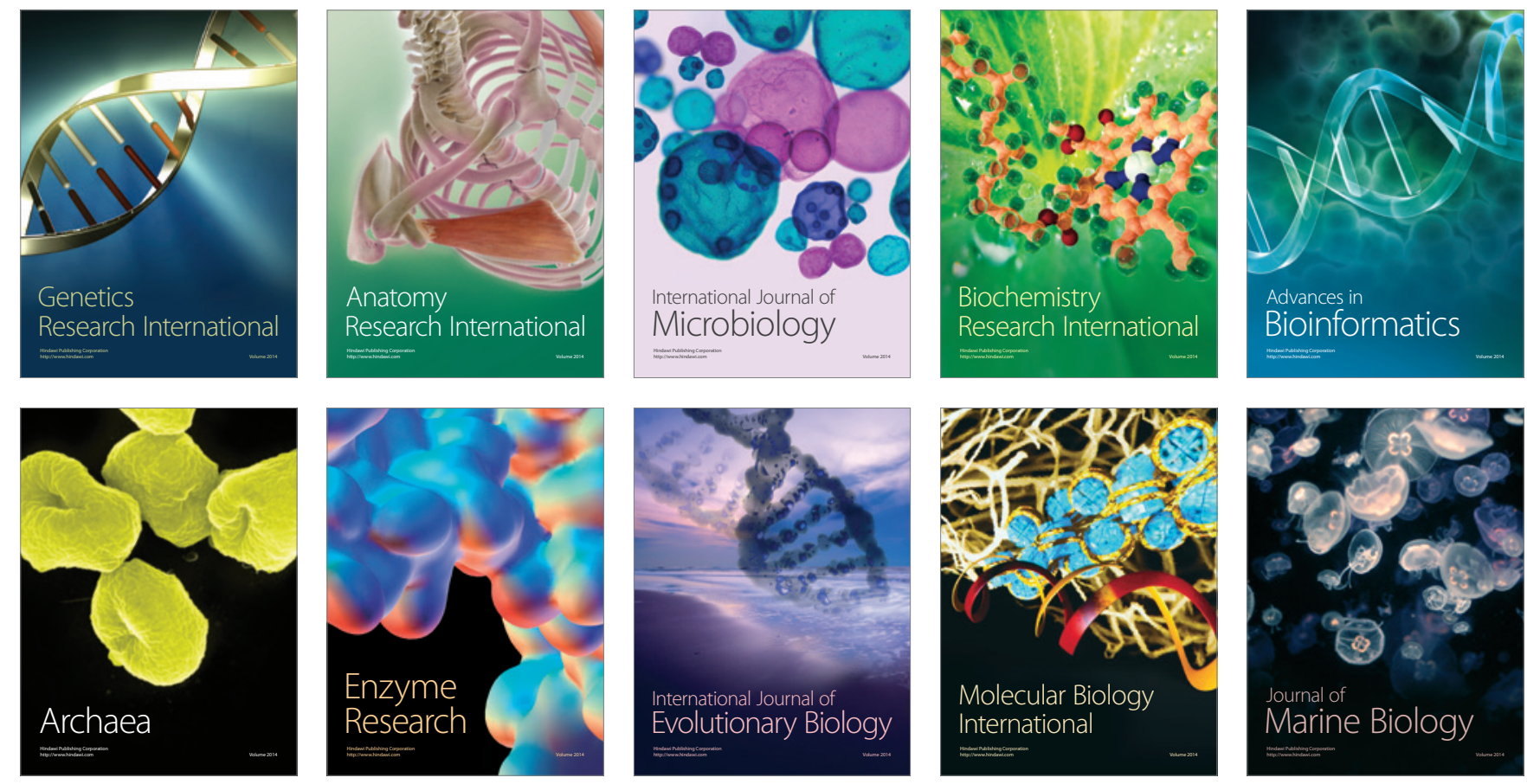